\title{
Ensino por investigação e Ciências Forenses: possibilidades para a alfabetização científica
}

\author{
Inquiry-based teaching and Forensic Sciences: possibilities to scientific literacy \\ Enseñar a través de la investigación y las Ciencias Forenses: posibilidades para la alfabetización \\ científica
}

Recebido: 14/01/2022 | Revisado: 19/01/2022 | Aceito: 26/01/2022 | Publicado: 27/01/2022

\author{
Adjane da Costa Tourinho e Silva \\ ORCID: https://orcid.org/0000-0001-8996-0689 \\ Universidade Federal do Sul e Sudeste do Pará, Brasil \\ E-mail: adtourinho@terra.com.br \\ Fernanda Carla Lima Ferreira \\ ORCID: https://orcid.org/0000-0002-1671-533X \\ Universidade Federal do Sul e Sudeste do Pará \\ E-mail: fernacarlaluan@gmail.com \\ Fernanda dos Santos \\ ORCID: https://orcid.org/0000-0002-0616-9734 \\ Universidade Federal de Sergipe, Brasil \\ E-mail: nandabarymore@hotmail.com \\ Aline Cunha da Silva \\ ORCID: https://orcid.org/0000-0003-2787-0092 \\ Universidade Federal do Sul e Sudeste do Pará \\ E-mail: alinecunha.ac5@gmail.com \\ Cindy Stella Fernandes \\ ORCID: https://orcid.org/0000-0002-0584-8495 \\ Universidade Federal do Sul e Sudeste do Pará \\ E-mail: cindy.fernandes@gmail.com
}

\begin{abstract}
Resumo
O ensino de ciências na perspectiva da alfabetização científica busca, além de proporcionar aos alunos a aprendizagem de conhecimentos científicos, a compreensão acerca dos modos de produção e legitimação de tais conhecimentos, bem como de suas relações com a sociedade e o meio ambiente, tendo em vista suas tecnologias. $\mathrm{O}$ engajamento dos alunos em atividades investigativas tem sido considerado como um meio fundamental para favorecer esta alfabetização. Neste artigo, a partir de um estudo bibliográfico, apresentamos uma discussão acerca do potencial da inserção de conteúdos das ciências forenses como temas para as atividades investigativas na Educação Básica. Tendo em vista que as ciências forenses já abrigam em si um caráter investigativo, consideramos também as possibilidades que abrem para que os alunos se envolvam com práticas de uma ciência aplicada, apropriando-se de conhecimentos científicos, além de perceberem estes em meio a situações que se apresentam em seu cotidiano, aliando aspectos sociais e ambientais. Somado a isso, evidencia-se a motivação dos alunos para se engajarem nas atividades e a oportunidade de conhecerem mais sobre o trabalho de peritos e desta área do conhecimento tão importante na sociedade contemporânea.
\end{abstract}

Palavras-chave: Ensino; Atividades investigativas; Ciências forenses; Alfabetização científica.

\begin{abstract}
The science teaching from the perspective of scientific literacy, seeks, beyond to provide students with the learning of scientific knowledge, to providing an understanding about the modes of production and legitimization of such knowledge, as well as its relationships with society and the environment, throughout of its technologies. The engagement of students in inquiry-based activities has been considered a fundamental means to promote scientific literacy. In this paper, based on a bibliographical study, we present a discussion about the potential of inserting content from forensic sciences as themes for investigative activities in school. Considering that the forensic sciences already have an investigative character in themselves, we also consider the possibilities that open up for students to become involved in the practices of an applied science, appropriating scientific knowledge, in addition to realizing it in situations that they see themselves in their day-by-day lives, combining social and environmental aspects. Added to this, the motivation of students to engage in activities and the opportunity to learn more about the work of experts and this area of knowledge that is so important in contemporary society.
\end{abstract}

Keywords: Teaching; Inquiry-based activities; Forensic sciences; Scientific literacy. 


\begin{abstract}
Resumen
La enseñanza de las ciencias desde la perspectiva de la alfabetización científica busca, además de facilitar a los estudiantes el aprendizaje del conocimiento científico, la comprensión de los modos de producción y legitimación de dicho conocimiento, así como de sus relaciones con la sociedad y el medio ambiente, teniendo en cuenta tus tecnologías. La participación de los estudiantes en actividades de investigación se ha considerado como un medio fundamental para promover esta alfabetización. En este artículo, con base en un estudio bibliográfico, presentamos una discusión sobre el potencial de insertar contenidos de las ciencias forenses como temas para actividades de investigación en la Educación Básica. Teniendo en cuenta que las ciencias forenses ya albergan un carácter investigativo, consideramos también las posibilidades que abren para que los estudiantes se involucren con prácticas de una ciencia aplicada, apropiándose del conocimiento científico, además de percibir estos en medio de las situaciones que se les presenten. en su vida diaria, combinando aspectos sociales y ambientales. Sumado a esto, se evidencia la motivación de los estudiantes para participar en actividades y la oportunidad de conocer más sobre el trabajo de los expertos y esta área del conocimiento tan importante en la sociedad contemporánea.
\end{abstract}

Palabras clave: Enseñanza; Actividades de investigación; Ciencias forenses; Alfabetización científica.

\title{
1. Introdução
}

A aprendizagem das Ciências da Natureza, tais como a Física e a Química, demanda um elevado nível de abstração, o que requer do professor um significativo investimento para que os alunos possam elaborar relações consistentes entre os níveis macroscópico e submicroscópico destas ciências. Saber lidar com as entidades criadas por meio do discurso científico acerca dos objetos reais com os quais os indivíduos se deparam, exige um diálogo entre empiria e teoria que está no cerne da aprendizagem, tornando-se fundamental para que os alunos possam dar sentido aos conceitos, princípios e leis que lhes são apresentados nas aulas. Isso envolve o desenvolvimento de certos esquemas cognitivos dos alunos, aliado, ainda, à motivação para aprender.

O ensino de ciências, todavia, de acordo com os pressupostos da alfabetização científica, não visa apenas à aprendizagem conceitual, mas uma compreensão acerca da Natureza da Ciência e de suas relações com aspectos tecnológicos, sociais e ambientais. Assim, os conhecimentos e habilidades almejados nessa perspectiva podem ser distribuídos em três grandes eixos estruturantes, como discutido por Sasseron e Carvalho (2011): A aprendizagem de conhecimentos e conceitos fundamentais da ciência; a aprendizagem acerca da Natureza da Ciência e dos fatores éticos e políticos que circundam sua prática e o entendimento das complexas relações entre ciência, tecnologia, sociedade e meio ambiente.

O primeiro desses três eixos estruturantes, refere-se à compreensão básica de termos, conceitos e princípios científicos fundamentais de diferentes campos disciplinares. Isso envolve a apropriação, pelos alunos, de conhecimentos necessários à aplicação na análise de informações e situações diversas com as quais se deparam em seu dia a dia. O segundo eixo diz respeito à compreensão de aspectos que se encontram na base dos processos de produção e legitimação dos conhecimentos científicos, tanto considerando-se características intrínsecas às investigações que se desenvolvem no interior dos laboratórios ou mesmo fora deles, quanto os aspectos que circundam a prática científica, como os éticos e políticos os quais, de alguma forma, interferem em seu desenvolvimento. Tal compreensão pode ser favorecida, dentre outras estratégias didáticas, por meio do ensino por investigação e também pela discussão de episódios da História da Ciência, na perspectiva de uma Abordagem Contextual (AC) como discutida por Mattews (1995). O terceiro eixo por fim, envolve as relações que o conhecimento científico mantém com a sociedade e o meio ambiente, levando-se em conta os artefatos tecnológicos que produz e disponibiliza às pessoas em geral e à própria comunidade científica.

$\mathrm{Na}$ perspectiva da alfabetização científica, espera-se que os alunos possam ter uma concepção mais adequada de ciência, considerando-se o seu caráter humano e social, de acordo com as contribuições dos estudos epistemológicos mais recentes, de modo que adquiram ferramentas necessárias para posicionarem-se de forma crítica na sociedade contemporânea, permeada por ciência e tecnologia. Trata-se de um ensino voltado para a formação do cidadão, entendido como o indivíduo que tem conhecimentos e capacidade crítica para a tomada de decisão. 
Assim, cabe refletir e pesquisar sobre estratégias de ensino adequadas que possam favorecer tanto a aprendizagem de conceitos, quanto aquelas relacionadas aos demais eixos que são pretendidos pelo ensino de ciências na perspectiva da alfabetização científica. Concordamos que um ensino por meio de atividades investigativas, as quais permitem aos alunos terem uma atitude ativa e dialógica, apresenta um grande potencial nessa direção, como bastante discutido na literatura da área (Silva \& Trivelato, 2017; Zômpero \& Laburú, 2016; Zômpero \& Laburú, 2011; Borges, et al., 2014; Nunes et al., 2018; Peres, 2006). Caso as investigações sejam decorrentes de temáticas sociais ou sócio ambientais, abre-se mais ainda tal potencial (Oliveira et al., 2021).

Na perspectiva de investir em temas e estratégias nessa direção, voltamo-nos para as ciências forenses, uma temática ainda pouco explorada no ensino de ciências, mas relativa a uma área de extrema importância em nossa sociedade. Tendo em vista que as ciências forenses já abrigam em si um caráter investigativo (Sebastiany et al., 2013; Santos \& silva, 2021) e envolvem conhecimentos de diversos campos, trazê-las para o ensino de ciências nos parece um caminho que muito contribuirá para a alfabetização científica dos alunos. Como discutido por Santos e Silva (2021), as ciências forenses podem favorecer os debates em torno de aspectos sociais, ambientais, econômicos, dentre outros, que auxiliam no desenvolvimento da argumentação e da capacidade crítica dos estudantes. Além disso, situações que envolvem a Química ou a Física forense, por exemplo, servem como suporte para despertar o interesse dos alunos por estas disciplinas (Dias Filho \& Antedomenico, 2010).

Neste artigo, nosso objetivo é apresentar uma discussão teórica sobre as relações entre ensino de ciências por investigação e ciências forenses, na perspectiva da alfabetização científica, verificando as potencialidades dessa relação para o ensino de ciências. Considera-se ainda alguns exemplos de trabalhos empíricos que se inserem nessa perspectiva. Espera-se que tal discussão possa favorecer a percepção da comunidade científica e pedagógica acerca das possibilidades de inserção de temas das ciências forenses na Educação Básica.

\section{Metodologia}

A pesquisa que dá origem a este artigo é de natureza teórica, sendo bibliográfica e exploratória. A fim de tecer as relações entre o ensino por investigação e as ciências forenses, na perspectiva da alfabetização científica, procedemos inicialmente a uma busca na literatura; em um primeiro momento voltada para à elaboração de uma discussão dos conceitoschave da pesquisa e seus pontos de interseção e, em seguida, considerando os trabalhos empíricos que envolvessem esta relação. A partir daí, desenvolvemos nossa análise.

Podemos sistematizar o estudo, com base em Salvador (1986), nos seguintes passos:

a) Levantamento bibliográfico: este levantamento, conforme comentamos, envolveu dois momentos. O primeiro voltado para textos (artigos e livros) que tratavam dos conceitos-chave da pesquisa e o segundo voltado para trabalhos empíricos (artigos) que envolvessem atividades investigativas com temas das ciências forenses na Educação Básica. No primeiro momento, levamos em conta obras de autores consagrados na literatura nacional e internacional sobre o tema. No segundo, procedemos uma busca no google scholar, tomando o espaço temporal de 10 anos (2011 a 2021) e utilizando os descritores "ensino por investigação" e "ciências forenses".

b) Levantamento das informações contidas na bibliografia: esta fase consistiu na reflexão crítica a partir do conhecimento acumulado a fim de gerar uma síntese, o "concreto pensado".

c) Análise explicativa: esta fase não esteve mais ligada à exploração do material pertinente ao estudo, mas envolveu a capacidade crítica para explicar ou justificar os dados e/ou informações contidas no material selecionado.

d) Síntese integradora: correspondeu ao produto final do processo de investigação, resultante da análise e reflexão acerca das ideias já esboçadas na fase anterior. 


\section{Alfabetização Científica e Ensino por Investigação}

\subsection{Alfabetização Científica}

Apesar das divergências que ocorrem na definição do termo alfabetização científica, este é usualmente empregado para designar um ensino de ciências voltado para a formação de um cidadão. Espera-se, portanto, que ao longo de sua escolarização os estudantes possam dominar basicamente determinados conhecimentos científicos, associados a uma concepção de ciência como atividade humana, social e cultural, de modo a utilizar tais conhecimentos para uma análise crítica e tomada de decisão frente as mais variadas situações sociais e ambientais com as quais se deparam. Isso envolve, por exemplo, desde suas opções alimentares, tendo em vista os diferentes tipos de alimentos à sua disposição (in natura, minimamente processados, processados e ultra processados), seu posicionamento em relação à construção de determinado tipo de usina (hidroelétrica, termoelétrica ou nuclear) em sua região, diante da mudança de curso de um rio ou diante do uso de vacinas para doenças que dizimam populações, até mesmo à opção por candidatos a cargos políticos em função de suas propostas sociais e ambientais. O fato é que vivemos em um mundo em que os conhecimentos científicos e suas tecnologias estão envolvidos em variadas questões da vida cotidiana, relacionando-se a aspectos sociais, ambientais, éticos e econômicos, de modo que, para se posicionar e atuar diante delas de maneira crítica, a alfabetização científica torna-se cada vez mais urgente.

Tendo em vista que a alfabetização científica demanda o desenvolvimento de uma série de conhecimentos e habilidades, alguns autores têm se ocupado em agrupá-los em função dos principais objetivos do ensino de ciências. Miller (1983), por exemplo, aponta três dimensões envolvidas no letramento científico (scientific literacy): i) o entendimento de normas e métodos da ciência; ii) a compreensão de termos e conceitos-chave das ciências; e, iii) o entendimento dos impactos das ciências e suas tecnologias. Essas três dimensões, de alguma forma, assemelham-se, respectivamente, àquelas discutidas por Sasseron (2008) e Sasseron \& Carvalho (2011), quais sejam: o conhecimento da Natureza da Ciência e dos fatores éticos e políticos que circundam sua prática, a aprendizagem de conhecimentos e conceitos fundamentais da ciência e a compreensão acerca das relações entre ciência, tecnologia, sociedade e meio ambiente.

Nessa mesma direção, Hodson (2014) considera 4 objetivos para o ensino de ciências:

\footnotetext{
Aprender ciência- adquirir e desenvolver conhecimento conceitual e teórico.

Aprender sobre ciências - desenvolver um entendimento das características da investigação científica, o papel e o status do conhecimento que ela gera, as circunstâncias sociais e intelectuais ao redor da origem e desenvolvimento de importantes teorias científicas, as formas com que a comunidade científica estabelece e monitora a prática profissional, incluindo conhecimento robusto das convenções linguísticas para relatar, defender, examinar e validar afirmações científicas e consciência das complexas interações entre ciência, tecnologia, sociedade e meio ambiente.

Fazer ciência - engajar-se e desenvolver experiência em investigação científica e solução de problemas.

Abordar questões sócio científicas (QSC) - desenvolver as habilidades críticas para confrontar os aspectos pessoais, sociais, econômicos, ambientais e éticos morais das QSC (Hodson, 2014, p. 2537. Tradução nossa. Grifos nossos).
}

É possível verificar que, apesar das distintas discussões acerca dos objetivos do ensino de ciências, as convergências entre elas são marcantes no tocante a proporcionar aos alunos: a aprendizagem dos conhecimentos produzidos pela ciência; o conhecimento acerca das formas como a ciência opera para a produção desses conhecimentos, o que envolve, além da compreensão e desenvolvimento de habilidades investigativas, a percepção de aspectos acordados pelas comunidades científicas, bem como suas relações com questões éticas, econômicas e políticas, dentre outras que interferem na sua prática; e a aprendizagem relacionada à compreensão acerca de como a ciência e a tecnologia se relacionam mutuamente com a sociedade e o meio ambiente. Hodson (2014) discute que a abordagem a tais relações é normalmente proporcionada por meio de problemas expressos nas denominadas questões sócio científicas (QSC).

Hodson $(1994,2014)$ chama atenção para o fato de que os professores devem estar atentos aos diferentes objetivos 
de aprendizagem, não devendo presumir que uma abordagem de aprendizagem bem-sucedida para um objetivo terá necessariamente sucesso em outro. Discute, assim, que se tem muitas vezes considerado que categorias de objetivos significativamente diferentes podem ser bem atendidas pelo mesmo tipo de experiência de aprendizagem. $\mathrm{O}$ autor tece, especificamente, críticas às grandes expectativas voltadas à experimentação e ao ensino por investigação como forma de alcançar todos os objetivos do ensino de ciências, com base na ideia de que se a investigação é central na ciência, também deve ser na ciência escolar.

Concordamos com o autor acerca da concepção de que determinadas estratégias de ensino podem ser mais adequadas a um ou a outro objetivo de aprendizagem. Por outro lado, é importante também considerar que, os objetivos do ensino de ciências dialogam entre si, de modo que eles se retroalimentam ao longo de abordagens que envolvem diferentes atividades, as quais se conciliam abarcando distintos objetivos. Isso pode ser melhor entendido considerando a discussão que Santos e ElHanni (2017) apresentam partindo da teoria de aprendizagem situada (Lave \& Wenger, 1991), a qual tem influenciado muitas pesquisas no âmbito educacional e contribuído para constituir uma perspectiva participacionista, a qual entende a aprendizagem como aprimoramento gradual da participação em práticas estabelecidas historicamente.

Lave e Wenger (1991), ao discutirem a aprendizagem como formas de participação em uma comunidade de prática, tentaram localizá-la em relações sociais, em situações de coparticipação, contrapondo-se à concepção de "aquisição" de certas formas de conhecimento. Tal participação não se "refere apenas a eventos pontuais de engajamento em certas atividades com certas pessoas, mas a um processo mais abrangente de ser participante ativo nas práticas de comunidades e na construção de identidades em relação àquelas comunidades" (Wenger, 1999, p.4). O argumento básico de Jean Lave e Etienne Wenger é que comunidades de prática existem em toda parte e estamos geralmente envolvidos em algumas delas - quer seja no trabalho, na escola, em casa, quer seja em nossas atividades cívicas ou de lazer. As salas de aula de ciências, portanto, podem ser percebidas como comunidades de práticas, em que os estudantes aprendem a se tornar cada vez mais hábeis no engajamento nas atividades desenvolvidas, considerando-se todas as habilidades e conhecimentos demandados.

Nesta perspectiva, Santos e El-Hanni (2017) consideram que o fazer ciência apontado por Hodson (2014) deve ser visto como o objetivo primeiro da educação científica, como condição sine qua non para o alcance dos demais objetivos de aprendizagem. Os autores argumentam que, se aprender é mudar a forma de participação numa prática discursiva, então, para aprender o indivíduo precisa, primeiramente, estar participando dessa prática. Assim, o fazer ciência pode envolver desde novas maneiras de usar conceitos e de combiná-los em teorias, incluindo novas habilidades em procedimentos e técnicas, até o uso de teorias, técnicas e procedimentos como ferramentas para a investigação científica.

Sendo assim

(...) é recomendável que as aulas de ciências valorizem o ensino por investigação, o qual pode envolver diferentes temáticas, a fim de favorecer o processo de alfabetização científica, fornecendo subsídios que auxiliem os alunos a compreender e discutir os significados construídos pela ciência, bem como os modos dessa produção (Lima; Silva \& Souza, 2021).

\subsection{Ensino por investigação}

Há um vasto número de pesquisas voltadas ao ensino por investigação. Este, por sua vez, adquiriu ao longo das últimas décadas um sentido bastante diferente daquele que lhe foi conferido no Modelo de Aprendizagem por Descoberta, muito difundido nas décadas de 1960 e 1970. Ancorada em uma perspectiva sociocultural, a concepção de investigação na ciência escolar envolve mais atualmente uma variedade de formas de lidar com os problemas investigativos, rompendo com a ideia de um método científico único, e fomentando a discussão e a prática argumentativa entre os pares para produzir e legitimar conhecimentos no plano social da sala de aula. Espera-se com isso que os alunos possam aprender sobre a Natureza 
da Ciência, ao tempo em que se envolvem na apropriação e construção de conhecimentos científicos. O uso de temas sociais, associados aos científicos, possibilitam também explorar as relações entre ciência, tecnologia, sociedade e meio ambiente.

Apesar da variedade de definições, pode-se considerar que o ensino por investigação se caracteriza por envolver os alunos no "processo de propor questões, gerar e desenvolver estratégias para responder tais questões, produzindo dados, analisando e interpretando tais dados, esboçando conclusões a partir deles, comunicando as conclusões, aplicando-as de volta à questão original e, talvez, seguindo novas questões que surgem (Sandoval, 2005. p. 636. Tradução nossa).

Abd-El-Khalick et al. (2004) discutem que o ensino por investigação é uma abordagem que auxilia o aluno a entender sobre a Ciência, os conteúdos produzidos por ela e sobre a natureza do conhecimento científico. Por meio deste ensino, os alunos desenvolvem habilidades científicas, tais como: reconhecimento de problemas que geram uma investigação; formulação, comunicação e defesa de hipóteses; e proposição de modelos e explicações que colocam à prova tais hipóteses. Para Sandoval (idem), de uma perspectiva epistemológica, investigar é simplesmente o processo de fazer ciência.

Como uma abordagem de ensino, a investigação pode situar-se ao longo de um contínuo que vai de menos a mais estruturada, com diferentes níveis de autonomia para os estudantes. Discussões relacionadas aos níveis de autonomia que são conferidos aos estudantes ao longo de uma investigação tem gerado categorias de atividades investigativas (Silva; Gerolin \& Trivelato, 2018; Cardoso \& Scarpa, 2018; Borges, 2002) o que expressa a variedade de perfis de investigações na ciência escolar. Também há, na literatura, propostas de estruturas de sequências de ensino investigativas que favorecem ao professor o planejamento e proposição de investigações aos alunos (Carvalho, 2013; Pedaste et al., 2015)

O ensino por investigação é implementado em sala de aula por meio de atividades investigativas ou sequências de ensino investigativas (SEI).

Consistindo em um conjunto de aulas planejadas de modo a possibilitar que as investigações aconteçam em sala de aula, as SEI envolvem uma série de atividades estruturadas e articuladas em prol da resolução de um problema de natureza científica ou sociocientífica, que se expressa por meio de uma ou mais questões (Oliveira; Cruz; Silva, 2020, p. 187).

Uma grande preocupação relativa a este ensino é o quanto ele de fato é colocado em prática nas escolas e, se isso acontece, em que medida ele se aproxima do que é discutido no campo da pesquisa e apresentado nas propostas curriculares nacionais. Nesse sentido, pensar em diferentes contextos de instauração de um ensino por investigação é algo que requer atenção. Conforme discutimos na introdução deste artigo, explorar temas das ciências forenses pode ampliar as opções para pôr em prática atividades investigativas, mobilizar os alunos para o engajamento, bem como conhecer esse campo do conhecimento pouco divulgado na Educação Básica, porém, cada vez mais importante em nossa sociedade.

\section{As Ciências Forenses e sua Inserção em Atividades Investigativas na Ciência Escolar}

\subsection{Ciências Forenses e ensino de ciências}

As ciências forenses são compostas por todos os conhecimentos científicos e técnicos utilizados para apurar crimes e assuntos legais diversos, tais como cíveis, penais ou administrativos (Barros et al., 2021; Agostini, 2015). Envolvem, assim, um conjunto de disciplinas e tecnologias científicas admissíveis para compor provas nos tribunais ou elucidar casos que necessitem de investigação. Trata-se de um campo interdisciplinar de conhecimento, envolvendo a Física, Biologia, Química, Medicina Legal, Antropologia, Toxicologia, Tanatologia, Anatomia Patológica, Balística, Criminalista, Odontologia, Psiquiatria, Psicologia, Radiologia, entre outras. As ciências forenses encontram-se em contínua expansão, de modo que suas metodologias, tecnologias e disciplinas permanecem em constante aperfeiçoamento (Agostini, 2015).

Considera-se que a utilização de conhecimentos científicos em auxílio a questões judiciais teve seu início registrado 
na antiga Grécia, com contribuições da química para assuntos da medicina. Tais ciências mostraram-se fundamentais também na Roma antiga para esclarecer casos de mortes por envenenamento, principalmente de figuras públicas (Mota \& Di Vitta, 2014). Também há registros de que as ciências médico-legais e as ciências de enfermagem teriam surgido interligadas no século XVII, quando os tribunais intimavam as parteiras a dar o seu parecer perante situações de gravidez, virgindade e violação sexual (Coelho, 2013).

Considerando-se a ciência forense moderna, destaca-se Mathieu-Joseph Bonaventura Orfila (espanhol, crescido na França, 1787-1853), considerado o pai da toxicologia. Atuando como perito em um caso de suspeita de assassinato por envenenamento, ele conseguiu provar a intoxicação por arsênio recolhendo amostras do corpo exumado da vítima, demonstrando que tal componente químico não era proveniente do solo onde o corpo havia sido enterrado. Nesse mesmo campo de atuação, ainda aparece o nome do químico inglês James Marsh (1794-1846), que desenvolveu também um teste para detecção de arsênio, o qual leva o seu nome. Outro nome bastante importante na história das ciências forenses é o de Edmond Locard (1877 - 1966), que dedicou sua vida à medicina legal e a estudos de criminalística (Mota \& Di Vitta, 2014).

Portanto, a junção de conhecimentos científicos com fins judiciários, não é recente. Todavia, a área forense vem ganhando destaque mais atualmente devido a séries e programas de televisão que fazem uso desse tema, tais como Bones, NCIS - Investigações Criminais e CSI (crime science investigation), os quais retratam a rotina de peritos, desvendando crimes através da ciência, o que tem atraído bastante o interesse pela área, sobretudo do público jovem (Cruz et al., 2016; Motta \& Di Vitta, 2014).

Mota e De Vitta (idem) observam que essa exposição na mídia permite a apresentação das ciências forenses como uma ciência aplicada, contribuindo para superar o estereótipo que ainda permanece no imaginário das pessoas de que a ciência é algo distante, desenvolvida por cientistas que se isolam em seus laboratórios e realizam experimentos de forma alheia a questões sociais. Tal exposição é vista também como positiva por aumentar o número de interessados por segmentos ligados às ciências forenses, podendo haver com isso mais estudos e trabalhos divulgados na área, aumentando o potencial de sua evolução.

O trabalho profissional do perito forense não se limita a laboratórios, visto que, muitas vezes, a perícia é realizada em locais externos, em que não é possível a realização de experimentos controlados. Tal fato pode comprometer o futuro de um julgamento, o que também justifica o investimento no desenvolvimento de técnicas melhores, mais eficientes e baratas, incluindo também instrumentos e equipamentos cada vez mais eficientes.

Pelo exposto, podemos considerar que a Ciência Forense trabalhada em sala de aula, além de ter o potencial de motivar os alunos para as atividades, permite o desenvolvimento de propostas didáticas interdisciplinares, possibilita o trabalho com conhecimentos científicos ao longo de investigações - na elucidação de crimes - bem como favorece a relação entre conhecimentos científicos e aspectos sociais e ambientais.

Por se caracterizar como uma área com temas transversais, a ciência forense pode propiciar a oportunidade de desenvolver atividades interdisciplinares no processo de ensino-aprendizagem. Dessa forma, torna-se bastante relevante para ser trabalhada em sala de aula por aplicar os conhecimentos científicos na resolução de crimes. Além de possibilitar que o aprendiz torne significativo o que aprende, esse tema traz para a escola a possibilidade de dar significado social à disciplina ensinada, ou seja, amplia a visão e orienta o discente (Cruz et al., 2016, p.167).

Convém salientar também que, o uso de temas das ciências forenses no ensino favorece a relação entre os conhecimentos teóricos e os conhecimentos prévios dos alunos e seu contexto social. Dessa forma, surge a possibilidade de se trabalhar o ensino por meio de temas norteadores, pautados no princípio da contextualização.

Apesar de uma parcela considerável da sociedade não ter conhecimento exato do que se trata, consegue enxergar que as ciências forenses estão relacionadas às investigações criminais e judiciais e, quando inserida no contexto escolar, torna-se 
uma ferramenta importante na divulgação e aprendizagem de ciências (Rosa et al., 2014).

\subsection{Ciências forenses, ensino por investigação e alfabetização científica}

Discutimos na seção 3.1 sobre a alfabetização científica e seus eixos estruturantes. Neste momento, vamos retomar tal conceito no sentido de analisar como a inserção de temáticas das ciências forenses no ensino de ciências pode contribuir para a alfabetização científica dos alunos.

Conforme verificamos, as ciências forenses abrigam em si um caráter investigativo, pois cabe a um perito forense examinar as causas de ou os responsáveis por crimes ou situações que necessitam de elucidação, reunindo provas que devem ser estabelecidas por meio de conhecimentos e procedimentos técnico-científicos. Desta forma, planejar e desenvolver sequências de ensino investigativas considerando temas das ciências forenses para aulas de Química e Física, por exemplo, possibilita aos alunos o fazer ciência, na forma de uma ciência aplicada, ao tempo em que estes se apropriam de conhecimentos da ciência. Nesse sentido, os alunos poderão lidar com elaboração de hipóteses, planejamento de experimentos, coleta e tratamento de dados e elaboração de conclusões, tendo em vista o problema investigativo proposto. Ao longo da sequência de ensino investigativa, desenvolverão também práticas discursivas, tais como a argumentação, a fim de defender as suas conclusões perante uma audiência - seus pares e o professor.

Nessa perspectiva, é possível constituir a sala de aula como uma comunidade de práticas em que os alunos possam cada vez mais se tornar familiarizados com atividades investigativas, tanto por meio de investigações científicas, quanto por meio de investigações sócio científicas, sendo que estas últimas podem envolver temas das ciências forenses. Trabalha-se, assim, com os três eixos estruturantes da alfabetização científica, conforme já discutido.

Torna-se importante ressaltar que, na elaboração e proposição de SEI para a Educação Básica, é fundamental ter em mente os critérios para a escolha dos temas, tendo em vista o que pode ser considerado para este nível de ensino, tanto em termos de conhecimentos envolvidos, quanto em condições para a prática de laboratório. Cabe ao professor fazer esta seleção. Todavia, vale lembrar que, na impossibilidade de obter os dados experimentais no laboratório escolar, estes, a depender do caso, podem ser fornecidos pelo professor (na forma de textos, tabelas ou gráficos), os quais serão submetidos à interpretação dos alunos. Isso é oportuno quando os dados são oriundos de aparelhos de difícil acesso, que exijam condições experimentais que não se encontram no laboratório escolar ou mesmo quando os experimentos oferecem riscos aos alunos. Outro ponto a considerar, é o de que nem toda atividade investigativa exige experimentação, assim como acontece em uma ação pericial. Nestes casos, descrições e fotos, por exemplo, podem ser apresentadas aos alunos e submetidas a análises. Danos e desastres ambientais ou urbanos se enquadram nessas situações.

\subsection{Alguns exemplos de atividades investigativas com temas das ciências forenses}

Abaixo, apresentamos dois casos de inserção de temas das ciências forenses na Educação Básica. O primeiro corresponde a uma SEI desenvolvida junto a Licenciandos em Química em uma disciplina da área pedagógica de uma universidade do nordeste. Foi utilizado o teste com rodizonato de sódio para detecção de resíduos de chumbo, a fim de identificar o autor de disparos de armas de fogo em um caso de crime fictício. O segundo corresponde a atividades investigativas envolvendo experimentos lúdicos aplicados a alunos do $9^{\circ}$ ano de uma escola pública, também para solucionar uma situação de crime fictício. Neste segundo caso, os alunos fizeram uso de técnicas forenses de revelação de impressões digitais, teste de DNA e identificação de sangue.

O primeiro trabalho é apresentado no artigo intitulado "Argumentação e outras práticas epistêmicas em uma sequência de ensino investigativa envolvendo Química Forense" (Santos \& Silva, 2021). Ele envolveu o desenvolvimento de uma SEI junto a licenciandos em Química, a fim de discutir as possibilidades de diferentes temas para o planejamento e realização de 
atividades investigativas, em que fosse valorizado o espaço para a argumentação e outras práticas epistêmicas. De acordo com a proposta, os licenciandos desenvolveram a SEI elaborando hipóteses, planejando um esquema experimental e analisando os dados obtidos a fim de identificar o autor de um assassinato que seguiu um roubo (caso fictício). Além de participarem, atuado como alunos, no desenvolvimento da SEI, os licenciandos analisaram-na, verificando suas potencialidades para a alfabetização científica e sugerindo alterações.

Consideramos este trabalho relevante, dentre outros aspectos, por retratar uma situação de inclusão de discussões sobre a possibilidade de considerar temas da Química Forense para desenvolver investigações na Educação Básica, na formação inicial de professores de Química. Apesar de envolver conhecimentos da Química, pouco se discute, na formação inicial do professor de Química, sobre tal área de conhecimento e suas contribuições para sociedade e educação.

O segundo trabalho é apresentado no artigo intitulado "A Ciência Forense no Ensino de Química por Meio da Experimentação Investigativa e Lúdica" (Cruz et al., 2016). Trata-se também de uma situação em que se lida com experimentos investigativos, desenvolvidos por alunos do $9^{\circ}$ ano de uma escola pública, a fim de solucionar um caso de assassinato considerando tanto a análise das digitais, quanto de sangue e DNA. Os autores destacam a motivação dos alunos para participação da atividade e o empenho na aprendizagem dos conceitos envolvidos. Vale destacar um trecho dos autores em que informam: “(...) na escola onde o trabalho foi executado, o sucesso foi tanto que a instituição já incorporou essa prática nas suas aulas de laboratório (...)" (Cruz et al., 2016, p. 171).

Ambos os trabalhos representam possibilidades de instauração do ensino por investigação na Educação Básica, na perspectiva da alfabetização científica, considerando temas das ciências forenses como mais um contexto de desenvolvimento dessa abordagem didática.

\section{Conclusão}

A pesquisa apresentada neste artigo teve por objetivo apresentar uma discussão sobre as relações entre ensino de ciências por investigação e ciências forenses, verificando as potencialidades dessa relação para a alfabetização científica dos alunos. Buscamos assim, apresentar características fundamentais da alfabetização científica e do ensino por investigação, a fim de, posteriormente, considerar como as ciências forenses trazidas para o contexto escolar, por meio de atividades investigativas, mostram-se frutíferas para este intento. Consideramos que, além do potencial de mobilizar os alunos para as aulas, conteúdos das ciências forenses podem ser trabalhados alcançando os três eixos estruturantes desse processo de alfabetização. Como se trata de um tema pouco explorado na Educação Básica, justifica-se, tendo em vista o potencial discutido, o investimento em pesquisas voltadas para a inserção de temas das ciências forenses neste nível de ensino. Assim, consideramos que a discussão apresentada neste artigo pode esclarecer professores e pesquisadores acerca do potencial da inserção de temas das ciências forenses na Educação Básica.

Percebemos, então, como oportuno, o investimento em pesquisas que envolvam a elaboração de sequências de ensino investigativas com foco em temas das ciências forenses e analisem as suas contribuições para a aprendizagem dos alunos, tendo em vista os diferentes eixos da alfabetização científica, pois a possibilidade de inserção de temas dessa esfera do conhecimento em sala de aula passa pelo investimento na produção de material didático com tal fim. Por outro lado, há que se instigar a inserção dessa discussão na formação inicial de professores de Ciências da Natureza a fim de habilitá-los nesse sentido e, sendo assim, a pesquisa neste nível de ensino torna-se também necessária.

No tocante às pesquisas envolvendo a elaboração de sequências de ensino investigativas, sugerimos que sejam explorados outros temas além dos crimes de roubos e homicídios já encontrados na literatura. Conforme comentamos, as ciências forenses consistem em um campo interdisciplinar, com uma variedade de conhecimentos e tecnologias científicas voltadas à elucidação de vários tipos de casos que necessitam de investigação. Temas tais como desastres e crimes ambientais 
constituem-se em uma boa opção para se investir. Entendemos que as questões ambientais podem gerar importantes discussões envolvendo aspectos políticos, sociais e econômicos relativos à preservação do meio ambiente em nosso país, que merecem ser trazidas para a sala de aula, sendo imprescindíveis para a formação do cidadão.

\section{Agradecimentos}

As autoras agradecem à FAPESPA, Termo de Outorga N . 008/2021/FAPESPA, pelo aporte financeiro.

\section{Referências}

Abd-el-Khalick, F., Boujaoude, S., Duschl, R., Lederman, N. G., Mamlok-Naaman, R., Hofsteain, A., Niaz, M., Treagust, D., \& Tuan, H. (2004). Inquiry in science education: international perspectives. Science Education, 88(3), 397-419

Agostini G. (Org.). (2015). Ciências Forenses: ao alcance de todos. Perse.

Barros, F., Kuhnen, B., Serra, M.C., \& Fernandes, C. M. S. (2021). Ciências forenses: princípios éticos e vieses. Revista Bioética, $29(1)$, 55-65.

Borges, A.T. (2002). Novos rumos para o laboratório escolar de ciências. Caderno Brasileiro de Ensino de Física, 19(3), 291-313.

Borges, D. R., Silva, A.C.T, Nascimento, E., \& Freire, F. A. (2014). Movimentos epistêmicos de uma professora em uma atividade investigativa de ciências. Scientia Plena, 10(4), 1-12.

Cardoso, M. J. C., \& Scarpa, D. L. (2018). Diagnóstico de elementos do ensino de ciências por investigação (DEENCI): uma ferramenta de análise de propostas de ensino investigativas. Revista Brasileira de Pesquisa em Educação em Ciências, 18(3), 1025-1059

Carvalho, A. M. P. (2013). O ensino de ciências e a proposição de sequências de ensino investigativas. In: Carvalho, A. M. P (Org.). Ensino de ciências por investigação: condições para implementação em sala de aula. Cengage Learning, 1-19.

Coelho, M. A. A. Impacto da Formação em Ciências Forenses. Viseu. Dissertação [Mestrado Enfermagem Médico-Cirúrgica] - Escola Superior de Saúde Viseu; 2013.

Cruz, A. A. C., Ribeiro, V. G. P., Longhinotti, E., \& Mazzetto, S. E. (2016). A Ciência forense no ensino de química por meio da experimentação investigativa e Lúdica. Química Nova na Escola, 38(2), 167-172.

Dias Filho, C. R., \& Antedomenico, E. (2010). A perícia criminal e a interdisciplinaridade no ensino de ciências naturais. Química Nova na Escola, 32(2), 6772 .

Hodson, D. (1994). Hacia un enfoque más critico del trabajo de laboratorio. Revista de Investigación y experiencias didácticas, 12(3), 299-313

Hodson, D. (2014). Learning science, learning about science, doing science: different goals demand different learning methods. International Journal Science Education, 36(15), 2534-2553.

Lave, J., \& Wenger, E. (1991). Situated learning: legitimate peripheral participation. Cambridge University Press.

Lima, G. P., Silva, A. C. T., Souza, D. N. (2021). Controvérsias sobre vacinas: o que pensam os estudantes? Revista Brasileira de Ensino de Ciências e Matemática, 4(2), 646-669.

Mattews, M. R. (1995). História, filosofia e ensino de ciências: a tendência atual de reaproximação. Caderno Catarinense de Ensino de Física, 12(3), 164-214.

Miller, J. (1983). Scientific literacy: a conceptual and empirical review. Daedalus, 12(2), 29-48.

Mota, L., \& Di Vitta, P. B. (2014). Química forense: utilizando métodos analíticos em favor do poder judiciário. Rev. Acad. Oswaldo Cruz, 1, 1-11.

Nunes, T. S., Castro, R. G., \& Motokane, M. T. (2018). Os diferentes gêneros textuais e a promoção da alfabetização científica: análise de uma sequência didática investigativa sobre biodiversidade. Revista Ciências \& Ideias, 9(2), 155-169.

Oliveira, F. S., Cruz, M. C. P., \& Silva, A. C. T. (2020). Desenvolvimento de argumentação em uma sequência de ensino investigativa sobre termoelétrica. Química Nova na Escola, 42(2), 186-201.

Oliveira, F. S., Cruz, M. C. P., \& Silva, A.C.T. (2021). Argumentação sociocientífica em torno da implantação de uma usina termoelétrica em Sergipe. Química Nova na Escola, 43(1), 105-118.

Pedaste, M., Mäeots, M., Siiman, L., Jong, T., Riesen, S., Kamp, E., Manoli, C., Zacharia, Z., \& Tsourlidaki, E. (2015). Phases of inquiry-based learning: definitions and the inquiry cycle. Educational Research Review, 14, 47-61.

Peres, G. J. (2006). Atividade investigativa na formação de professores das séries iniciais do ensino fundamental. Escritos sobre educação, 5(1), 13-18.

Rosa, M. F., Silva, O. S., \& Galvan, F. B. (2014). Ciência forense no ensino de química por meio da experimentação. Química Nova na Escola, 00(0): 1-9.

Salvador, A. D. (1986). Métodos e técnicas de pesquisa bibliográfica (7ª ed.). Porto Alegre: Sulina editora. 
Research, Society and Development, v. 11, n. 2, e36111225775, 2022

(CC BY 4.0) | ISSN 2525-3409 | DOI: http://dx.doi.org/10.33448/rsd-v11i2.25775

Sandoval, W. A. (2005). Understanding student's pratical epistemologies and their influence on learning through inquiry. Science Education, 89(4), 634-656.

Santos F., \& Silva, A. C. T. (2021). Argumentação e outras práticas epistêmicas em uma sequência de ensino investigativa envolvendo química forense. Química Nova na Escola, 43(2), 205-223.

Santos, V. C., \& El-Hani, C. (2017, novembro). Fazer ciência, abordar questões sociocientíficas: diferentes objetivos demandam diferentes participações discursivas. Anais do Encontro Nacional de Pesquisa em Educação em Ciências, Florianópolis, SC, Brasil, 11.

Sasseron, L. H., Carvalho, A. M. P. (2011). Alfabetização científica: uma revisão bibliográfica. Investigações em Ensino de Ciências, 16(1), 59-77.

Sasseron, L. H. (2008). Alfabetização científica no ensino fundamental: estrutura e indicadores deste processo em sala de aula. Tese de Doutorado, Universidade de São Paulo, Faculdade de Educação, São Paulo, SP, Brasil.

Sebastiany, A. P., Pizzato, M. C., \& Salgado, T. D. M. (2015). Aprendendo a investigar através de uma atividade investigativa sobre ciência forense e investigação criminal. Revista Brasileira de Ensino de Ciência e Tecnologia, 8(4), 252-287.

Silva, M. B., Gerolin, E. C., \& Trivelato, S. L. F. (2018). A importância da autonomia dos estudantes para a ocorrência de práticas epistêmicas no ensino por investigação. Revista Brasileira de Pesquisa em Educação em Ciências, 18(3), 905-933.

Silva, M. B., \& Trivelato, S. L. F. (2017). A mobilização do conhecimento teórico e empírico na produção de explicações e argumentos numa atividade investigativa de biologia. Investigações em ensino de ciências, 22(2),139-153, http://dx.doi.org/10.22600/1518-8795.ienci2017v22n2p139

Wenger, E. (1999). Communities of practice: learning, meaning and identify. Cambridge University Press.

Zômpero, A. F., \& Laburú, C. A. (2011). Atividades investigativas no ensino de ciências: aspectos históricos e diferentes abordagens. Revista Ensaio, 13(03), $67-80$.

Zômpero, A. F., \& Laburú, C. E. (2017). Implementação de atividades investigativas na disciplina de ciências em escola pública: uma experiência didática. Investigações em ensino de ciências, 17(3), 675-684. 